American Journal of Biochemistry and Biotechnology 7 (1): 21-28, 2011

ISSN 1553-3468

(C) 2010 Science Publications

\title{
Soluble CD14, Sialic Acid and L-Fucose in Breast Milk and their Role in Increasing the Immunity of Breast-Fed Infants
}

\author{
${ }^{1}$ Ghalib Ali Oriquat, ${ }^{2}$ Tahia H. Saleem, ${ }^{3}$ Samir T. Abdullah, \\ ${ }^{3}$ Gamal T. Soliman, ${ }^{4}$ Reda S. Yousef, ${ }^{3}$ Abdellah M. Adel Hameed and ${ }^{1}$ Maher L. Salim \\ ${ }^{1}$ Faculty of Pharmacy and Medical Sciences, Al-Ahliyya Amman University, Jordan \\ ${ }^{2}$ Department of Medical Biochemistry, Faculty of Medicine, Assiut University, Egypt \\ ${ }^{3}$ Department of Pediatric, Faculty of Medicine, Al-Minia University, Egypt \\ ${ }^{4}$ Department of Biochemistry, Faculty of Medicine, Sohag University, Egypt
}

\begin{abstract}
Problem statement: Breast milk contain protective factors as soluble CD14, L-Fucose and Sialic acid which increase the innate immunity and level of intelligence, decrease the incidence of gastroenteritis, chest and other systemic diseases in newly born infants. In the present study the role of soluble CD14, L-Fucose and Sialic acid, in increasing the immunity in breastfed infants were studied to establish the previously unrecognized function and their broader spectrum of activities. Approach: The study was carried out with three different groups of breastfed neonates/infants; In group-I twenty full term neonate aging from (1-29 days), group-II fifteen pre-term neonates aging from (1-29 days) and in group-III fifteen infants aging from (61-730 days) were selected and their health were studied. Results: The results showed that the levels of sCD14 were $16.47 \pm 5.50,17.07 \pm 5.86$ and $15.10 \pm 3.45 \mu \mathrm{g} \mathrm{mL}^{-1}$ in full term, pre-term and 2-years group respectively. The levels of sialic acid were 2.5 -3 folds higher in group-I $\left(3.29 \pm 1.34 \mathrm{mmol} \mathrm{L}^{-1}\right)$ and group-II $\left(3.99 \pm 1.32 \mathrm{mmol} \mathrm{L}^{-1}\right)$, as compared to group-III $\left(1.30 \pm 0.16 \mathrm{mmol} \mathrm{L}^{-1}\right)$ repectively. Similarly, the level of L-Fucose was 1.5 folds higher in group-I $\left(8.84 \pm 0.34 \mathrm{mmol} \mathrm{L}{ }^{-1}\right)$ and group-II $\left(8.92 \pm 0.37 \mathrm{mmol} \mathrm{L}^{-1}\right)$ as compared to group-III $\left(5.80 \pm 1.96 \mathrm{mmol} \mathrm{L}^{-1}\right)$. Conclusion: Breast milk contains a variety of antimicrobial substances (relatively resistant against intestinal proteolysis) that functions in safeguarding the lactating mammary gland and provides protection to the suckling infant at a time when its immune system is still immature, some of these substances include sCD14, Sialic acid and L-Fucose. Hence, it is recommended to breastfeed the neonates/infants to enhance their immunity.
\end{abstract}

Key words: Soluble CD14 (sCD14), L-fucose, sialic acid, breast milk, innate immunity, Secretary Toxins (ST), Human Milk Oligosaccharides (HMOs), predominantly macrophages, foreign antigen, producing cells, lactating mammary, inflammatory cytokines

\section{INTRODUCTION}

Neonates are exposed to a large number of microorganisms, foreign proteins, chemicals and resistance to infection relies both on the protective factors in milk and on the infant developing his/her own innate and adaptive (antigen-driven) immunity. The neonatal immune system functions differently from that of an adult. Whether one can define the infant's immune system as classically "immunosuppressed" is somewhat debatable. Because antigen exposure occurs in uterus, from an immunological stand point, the infant's cells require considerable "education" in the early postnatal period. T-cell immaturity is contributed by deficiencies in antigen presentation (Kelly and Couttes, 2000).
Together the native and altered cytokine response by the infant's immune system will contribute to lower immune competence in the infant. As a result, inflammatory cells of the innate immune system, predominantly macrophages and neutrophils, become responsible for the clearance of foreign antigen. At birth, cells of the innate immune system (macrophages, neutrophils, dendrites cells) and IgM- and IgG-producing cells are present in the intestine, but mucosal IgA cells are either absent or extremely rare (Brandtzaeg, 2003).

Breast milk contains a variety of antimicrobial substances (relatively resistant against intestinal proteolysis) that function to both safeguard the lactating mammary gland and provide protection to the suckling infant at a time when its immune system

Corresponding Author: Ghalib Ali Oriquat, Faculty of Pharmacy and Medical Sciences, Al-Ahliyya Amman University, Al-Ahliyya Amman University Post Office Amman 19328, Jordan . Tel: 0962-795901579 
is still immature (Hanson et al., 2003a; 2003b). Human milk contains oligosaccharides that are not digestible to the infant and remain largely intact until they reach the large intestine, where they can be used by beneficial intestinal bacteria. Recent evidence suggests that the structure of the oligosaccharide plays a role on how it is fermented (Ward et al., 2006; LoCascio et al., 2007; Ninonuevo et al., 2007).

Cytokines are small-secreted proteins, which mediate and regulate immunity, inflammation and hematopoiesis. They must be produced denovo in response to an immune stimulus. They generally (although not always) act over short distances and short time spans and at very low concentration. They act by binding to specific membrane receptors, which then signal the cell via second messengers, often tyrosine kinases, to alter its behavior (gene expression). Responses to cytokines include increasing or decreasing expression of membrane proteins (including cytokine receptors), proliferation and secretion of effector molecules (Calisher, 2008).

CD 14 is a glycosyl-phosphatidyl-inositol anchored membrane protein (mCD14) expressed on mature monocytes (Ulevitch and Tobias., 1995). It functions as a co-receptor for bacterial Lipopolysaccharide (LPS) and triggers the induction of inflammatory responses (Wright et al., 1990). One consequence of LPSmediated monocyte activation is the release of soluble CD14 (sCD14) (Bazil and Strominger, 1991) and increased levels of circulating sCD14 correlate with infection and autoimmunity (Yu et al., 1998). Soluble CD14 (sCD14) has been postulated to desensitize monocytes through blunting their production of inflammatory cytokine in response to endotoxin.

However, this role remains contentious, as humans respond immediately and briskly to endotoxin despite containing 1,000-fold molar excess of serum sCD14 relative to the concentration of LPS observed during sepsis. The present study establishes a previously unrecognized function of sCD14 and demonstrates its broader spectrum of biological activities. After birth, the sterile fetal intestine is heavily colonized mainly by Escherichia coli and Streptococci (Mackie et al., 1999)

Sialic acids are a family of nine-carbon acidic monosaccharide's that occur naturally at the end of sugar chains attached to the surfaces of cells and soluble proteins. In the human body, the highest concentration of Sialic acid (as N-acetylneuraminic acid) occurs in the brain where it participates as an integral part of ganglioside structure in synaptogenesis and neural transmission. Human milk also contains a high concentration of Sialic acid attached to the terminal end of free oligosaccharides, but its metabolic fate and biological role are currently unknown. An important question is whether the Sialic acid in human milk is a conditional nutrient and confers developmental advantages on breast-fed infants compared to those fed infant formula (Wang and Brand-Miller., 2003). The high fructose diet can induce significant elevation in the level of sialic acid. The increased level of sialic acid was strongly related to the presence of microvascular complications and cardiovascular risk factor like hypertension (Mahfouz et al., 2010).

Several possible functions have been suggested for sialylated oligosaccharides. They act as receptors to pathogens, thereby inhibiting pathogen binding to epithelial cell surfaces. Additionally, Sialic acids increase the production of gangliosides, important components in membrane receptors and cell surfaces of the nervous system. All mammals have the capacity to synthesize Sialic acids; however, newborn infants typically incorporate exogenous Sialic acids because of their immaturity and the rapid growth and development of the brain exceeds their capacity to produce it (Bao et al., 2007).

L-Fucose (6-deoxy-L-galactose) is a monosaccharide found in glycoprotein and cell wall polysaccharides, such as xyloglucan and rhamnogalacturonans I and II. Knowledge about a carbohydrate fraction, distinct from lactose in human milk goes back $>100$, whereas the structures of Human Milk Oligosaccharides (HMOs) were unknown for a long time.

In the present study we studied the levels of soluble CD14, Sialic acid and L-Fucose in breast milk and their roles in increasing the immunity of the breast- fed infants.

Subjects and methods: The present study included 50 women and their neonates and infants. They are recruited from out-patients' clinic of pediatrics and inpatients' of pediatric, obstetrics and gynecology department, Assiut University, Egypt. These were divided into three groups:

- Group-I: included 20 mothers (their age ranged from 20-30 years with their 20 full-term neonate aged from 1-29 days)

- Group-II: included 15 mothers (their age ranged from 21-30 years with their 15 pre-term neonate aging from 1-29 days)

- Group-III: included 15 mothers (their age ranged from 19-30 years with their 15 infants aging from $61-730$ days) 
The neonates and infants of each group were subjected to the following.

History: Stressing on gestational age, gastrointestinal troubles, chest and cardiac symptoms and signs were recorded.

Medical examination:

- Cardiovascular system: Heart rate, presence of cyanosis and murmurs

- Respiratory system: Inspection of palpitation by percussion and auscultation

- Abdominal examination: Abdominal distention and organomegally

- Neurological examination: Irritability, tone, convulsions, state of consciousness, reflexes, abnormal movements and paralysis.

\section{MATERIALS AND METHODS}

About $5 \mathrm{~mL}$ of breast milk was expressed in a clean container from each mother's colostrums and mature milk were collected and centrifuged at $3000 \mathrm{~g}$ for $30 \mathrm{~min}$. The fat layer was removed and the remaining part stored at $-80^{\circ} \mathrm{C}$ until time of estimation:

- Soluble CD14 was measured by ELISA (enzyme linked immunosorbent assay) kit (code: DKH780 Format: $1 \times 96$ tests).

- Sialic acid was measured by reported method (Plucinksy et al., 1986)

- L-Fucose was measured in breast milk using reported method (Lopes and Gasper, 2008)

\section{RESULTS}

The demographic data (mean age, sex ratio and mean weight) of the studied groups are mentioned in Table 1 and Fig. 1-3. The average weight was ranged from $3.72-7.55 \mathrm{~kg}$.

\section{Physical examination:}

Vital signs: There were no significant differences in respiratory rate when the three groups compared together. However; there was a significant $(\mathrm{p}>0.0001)$ increase in heart rate in group-I and in group-II when each group was compared to group-III, (Table 2 and Fig. 4-5).

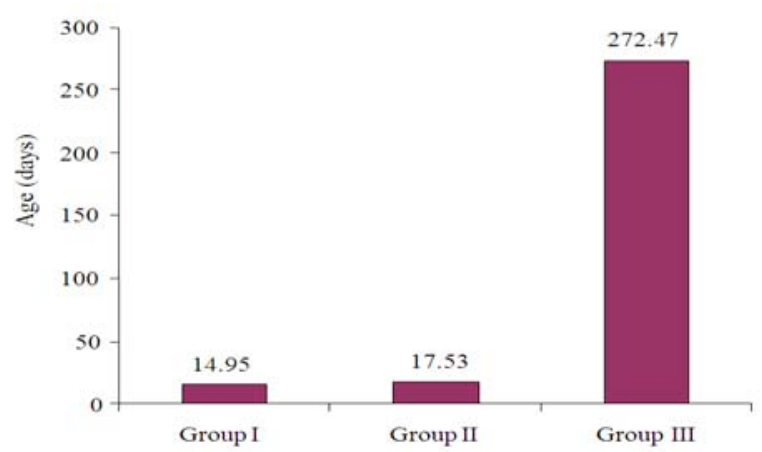

Fig. 1: Mean age (days) in the studied groups

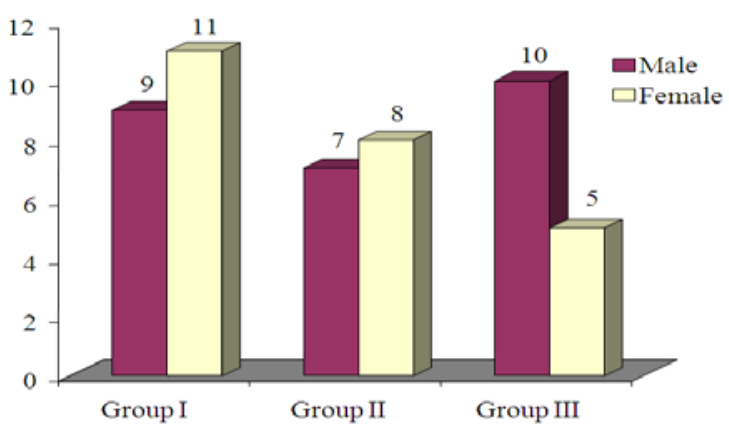

Fig. 2: Sex distribution in the studied groups

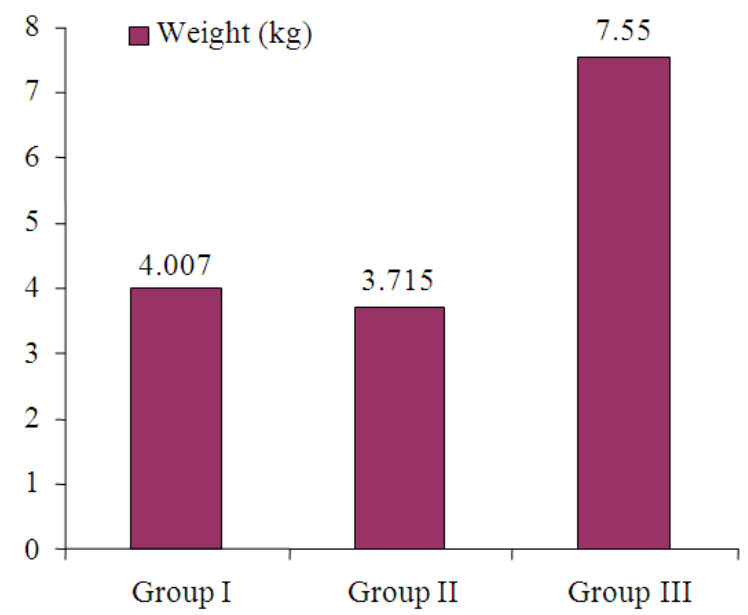

Fig. 3: Mean weight (kg) in the studied groups

Table 1: Demographic data of the studied groups

\begin{tabular}{llll}
\hline Variable & Group-I $(\mathrm{N}=20)$ & Group-II $(\mathrm{N}=15)$ & Group-III $(\mathrm{N}=15)$ \\
\hline Age (days) & $14.95 \pm 13.1$ & $17.53 \pm 11.38$ & $272.47 \pm 169$ \\
Sex $(\mathrm{M} / \mathrm{F})$ & $/ 11$ & $7 / 8$ & $10 / 5$ \\
Weight $(\mathrm{kg})$ & $4.007 \pm-0.70$ & $3.715 \pm-0.79$ & $7.55 \pm 1.76$ \\
\hline
\end{tabular}


Am. J. Biochem. \& Biotech., 7 (1): 21-28, 2011

Table 2: Comparative respiratory rate (R.R.) and heart rate in the studied groups

\begin{tabular}{|c|c|c|c|c|c|}
\hline \multirow[b]{2}{*}{ Variable } & \multicolumn{3}{|l|}{ Mean \pm SD (range) } & \multirow[b]{2}{*}{ Comparison between } & \multirow[b]{2}{*}{ P-value } \\
\hline & Group-I $(\mathrm{N}=20)$ & Group (II) (N=15) & Group (III) (N=15) & & \\
\hline R.R. $\min ^{-1}$ & $34.85 \pm 6.04(25-44)$ & $37.13 \pm 11.2(28-74)$ & $30.67 \pm 6.12(20-42)$ & I Vs II & $0.44 \mathrm{NS}$ \\
\hline Heart rate (Beats $\mathrm{min}^{-1}$ ) & $111.40 \pm 15(89-135)$ & $111.47 \pm 13.9(88-135)$ & $88.60 \pm 6.10(80-105)$ & $\begin{array}{l}\text { I Vs III } \\
\text { II Vs III } \\
\text { I Vs II } \\
\text { I Vs III } \\
\text { I Vs III }\end{array}$ & $\begin{array}{l}0.52 \mathrm{NS} \\
0.06 \mathrm{NS} \\
0.85 \mathrm{NS} \\
0.0001 * * \\
0.0001 * *\end{array}$ \\
\hline
\end{tabular}

NS $=$ No significant difference, $* *=p>0.0001$ Significant difference

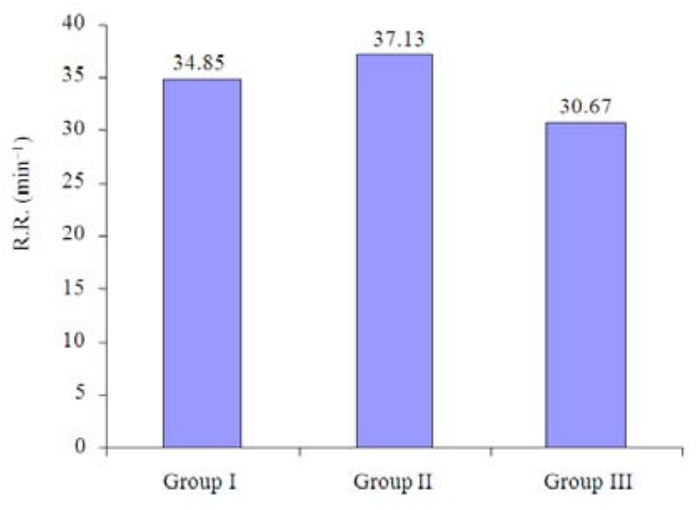

Fig. 4: Mean respiratory rate in the studied groups

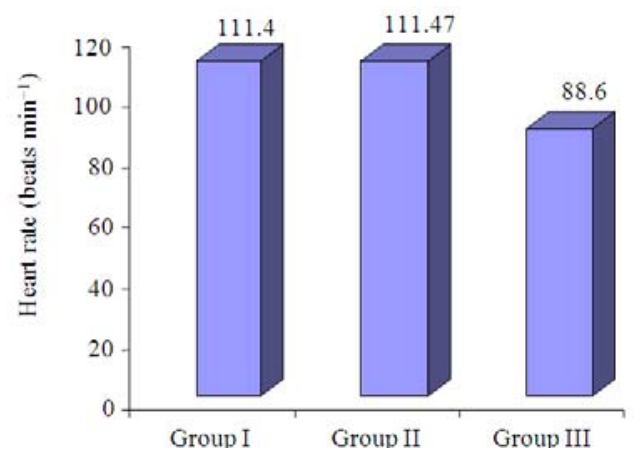

Fig. 5: Mean heart rate in the studied groups

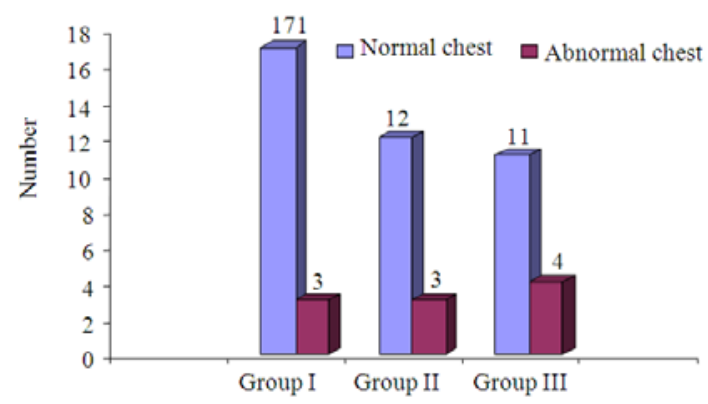

Fig. 6: Finding of chest examination in the studied groups
Table 3: Chest and heart examination in the studied groups

\begin{tabular}{llllll}
\hline & & \multicolumn{3}{c}{ Group-I Group-II Group-III } \\
Variable & Status & $(\mathrm{N}=20)$ & $(\mathrm{N}=15)$ & $(\mathrm{N}=15)$ & P-value \\
\hline Chest & Normal /Abnormal & $17 / 3$ & $12 / 3$ & $11 / 4$ & $0.69 \mathrm{NS}$ \\
Heart & Normal/Abnormal & $19 / 1$ & $13 / 2$ & $15 / 0$ & $0.29 \mathrm{NS}$ \\
\hline
\end{tabular}

NS: No Significant difference

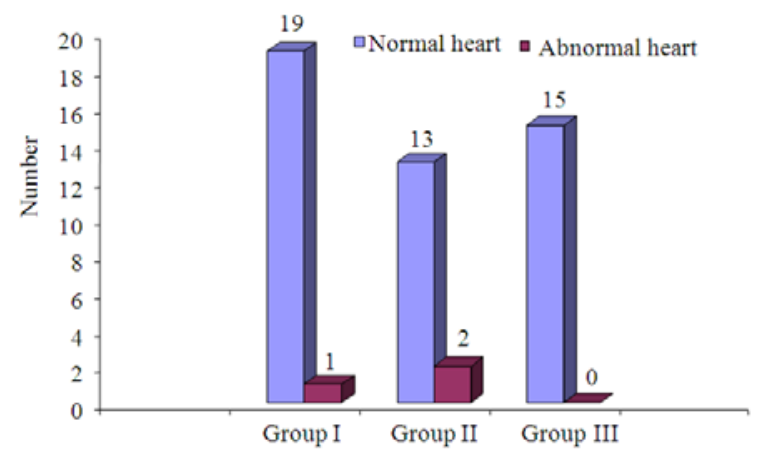

Fig. 7: Finding of heart examination in the studied groups

Systemic examination: Abnormal chest findings were uncounted in three cases in group-I and group-II and in four cases in group-III. The difference is not statistically significant between the groups.

Abnormal heart findings were uncounted in one case in group-I and two cases in group-II. No abnormalities were observed in group-III. The difference is not statistically significant between the groups (Table 3 and Fig. 6-7).

Levels of soluble CD14, Sialic acid and L-Fucose: Table 4 and Fig. 8 shows the levels of soluble CD14 in group-I (16.47 \pm 5.50$)$, group-II (17.07 \pm 5.86$)$ and groupIII $\left(15.10 \pm 3.45 \mu \mathrm{g} \mathrm{mL}^{1}\right)$.

There was no significant difference in the soluble CD14 level among these groups. The levels of Sialic acid were significantly higher in-group-I $(3.29 \pm 1.34$ mmol L $\left.{ }^{-1}\right)$ and group-II $\left(3.99 \pm 1.32 \mathrm{mmol} \mathrm{L} \mathrm{L}^{-1}\right)$ as compared to group-III $\left(1.30 \pm 0.16 \mathrm{mmol} \mathrm{L}^{-1}\right)$ ( $>00.0001) \quad$ (Table 4 and Fig. 9). 
Am. J. Biochem. \& Biotech., 7 (1): 21-28, 2011

Table 4: Soluble CD14 $\left(\mu \mathrm{g} \mathrm{mL}^{-1}\right)$, Total Sialic acid $\left(\mathrm{mmol} \mathrm{L}^{-1}\right)$ and Total L-Fucose $\left(\mathrm{mmol} \mathrm{L}^{-1}\right)$ content in the studied groups

\begin{tabular}{|c|c|c|c|c|c|}
\hline \multirow[b]{2}{*}{ Variable } & \multicolumn{3}{|l|}{ Mean \pm SD (range) } & \multirow[b]{2}{*}{ Comparison between } & \multirow[b]{2}{*}{ P-value } \\
\hline & Group-I $(\mathrm{N}=20)$ & Group (II) $(\mathrm{N}=15)$ & Group (III) $(\mathrm{N}=15)$ & & \\
\hline \multirow[t]{3}{*}{ Soluble CD14 $\left(\mu \mathrm{g} \mathrm{mL}^{-1}\right)$} & $16.47 \pm 5.5(12.7-24.8)$ & $17.07 \pm 5.86(11.8-28.7)$ & $15.10 \pm 3.45(8.55-19.93)$ & I Vs II & $0.71 \mathrm{NS}$ \\
\hline & & & & I Vs III & $0.26 \mathrm{NS}$ \\
\hline & & & & II Vs III & $0.27 \mathrm{NS}$ \\
\hline \multirow[t]{3}{*}{ Total Sialic acid $\left(\mathrm{mmol} \mathrm{L}^{-1}\right)$} & $3.29 \pm 1.34(1.89-5.21)$ & $3.99 \pm 1.32(2.41-5.97)$ & $1.30 \pm 0.16(1-1.57)$ & I Vs II & $0.13 \mathrm{NS}$ \\
\hline & & & & I Vs III & $0.0001 * *$ \\
\hline & & & & II Vs III & $0.0001 * *$ \\
\hline \multirow[t]{3}{*}{ L-Fucose $\left(\mathrm{mmol} \mathrm{L}^{-1}\right)$} & $8.84 \pm 0.34(8.45-9.5)$ & $8.92 \pm 0.37(8.53-9.45)$ & $5.80 \pm 1.96(3.6-8.85)$ & I Vs II & $0.54 \mathrm{NS}$ \\
\hline & & & & I Vs III & $0.0001 * *$ \\
\hline & & & & II Vs III & $0.0001 * *$ \\
\hline
\end{tabular}

NS $=$ No Significant difference, ${ }^{* *}=\mathrm{p}>0.0001$ Significant difference

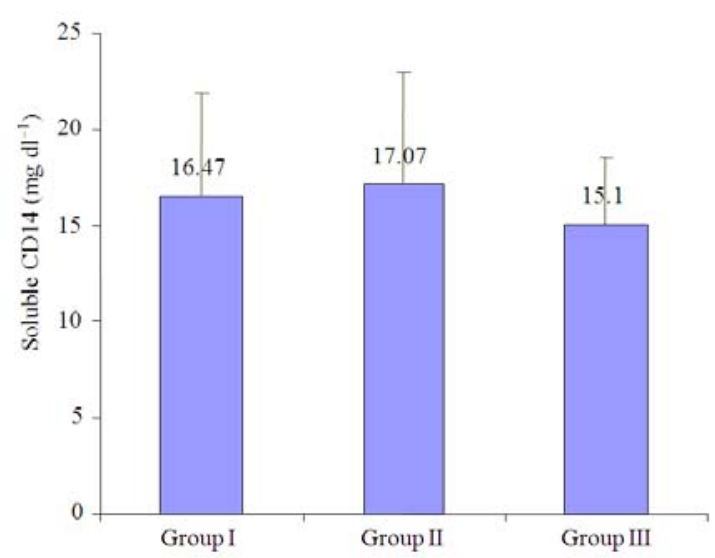

Fig. 8: Mean soluble CD14 $\left(\mu \mathrm{g} \mathrm{mL}^{-1}\right)$ in the studied group

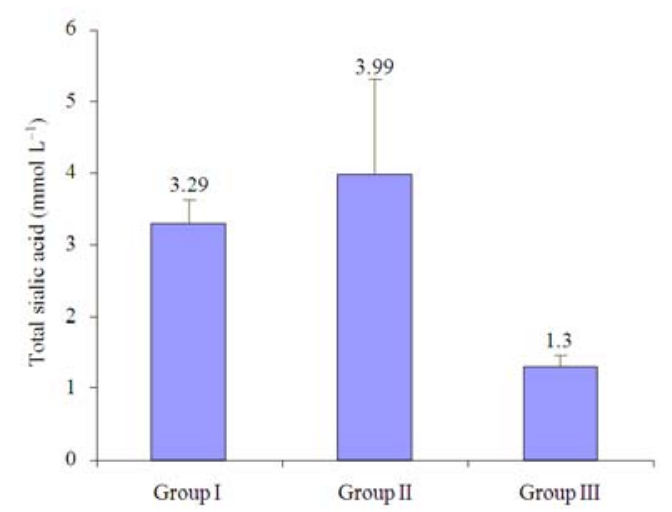

Fig. 9: Total Sialic acid (Mean, mmol L $\mathrm{L}^{-1}$ ) in the studied groups

So far as L-Fucose is concerned it ranged from $5.80 \pm 1.96-8.92 \pm 0.37 \mathrm{mmol} \mathrm{L}^{-1}$. The levels of L-Fucose were significantly higher in group-I $(8.84 \pm 0.34)$ and group-II $(8.92 \pm 0.37)$ as compared to group-III $\left(5.80 \pm 1.96 \mathrm{mmol} \mathrm{L}^{1}\right)(\mathrm{p}>0.0001)$ (Table 4 and Fig. 10).

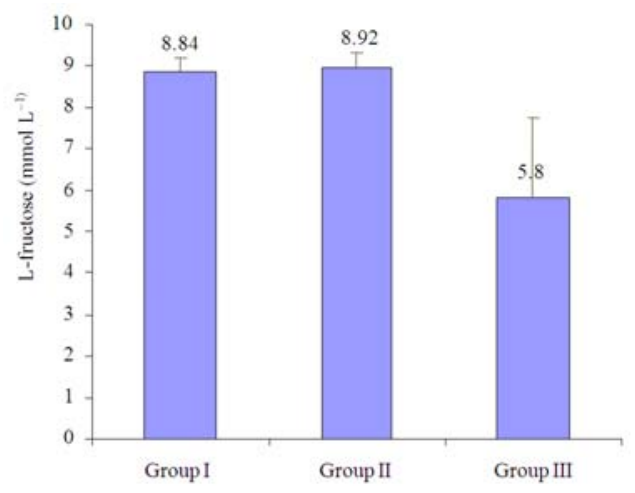

Fig. 10: L-Fucose (Mean, mmol L $\mathrm{L}^{-1}$ ) in the studied groups

\section{DISCUSSION}

There is a mixture of bioactive components in human milk that influence the immune status of infants by not only providing protection but also by facilitating development, tolerance and an appropriate inflammatory response. It could be suggested that milk is the communication vehicle between the maternal immune system and the infant, a system actively directing and educating the immune, metabolic and microflora systems within the infant, while conferring multiple means of protection from pathogens (Field, 2005).

The physiological and protective functions of many of the immune components in human milk have been deduced not from studies in infants but from what is known in other species and in vitro models. This update briefly reviews immune development in infants and focuses on current knowledge of how both the "classical" immune and the non-immune ingredients found in mature human milk promote immune development, facilitate the development of tolerance and regulate the inflammatory response of infants (Field, 2005). 
In the present study, we demonstrate some of these factors as soluble CD14, Sialic acid and L-Fucose and discuss their role in increasing the immunity of breastfed infants.

The present study was carried out on three groups; group (I) included (20) full term neonates aging from (1 29) days, group (II) included (15) pre-term neonates aging from (1 - 29) days and group (III) included (15) infants aging from (61-730) days.

The present study revealed that there were no significant differences, concerning the levels of soluble CD14 between different groups. The level of sCD14 in group-I, group-II and group-III were ranged from $15.10 \pm 3.45-17.07 \pm 5.86 \mu \mathrm{g} \mathrm{mL}^{-1}$.

In Labeta et al. (2000) reported that levels of sCD14 in multiple milk samples from 10 donors, taken at different times postpartum were very high $(52.9 \pm$ $\left.24.0 \mu \mathrm{g} \mathrm{mL}^{-1}\right)$. The highest sCD14 levels were detected in the relatively early samples $(<6 \mathrm{~d}, 67.09 \pm 27.61 \mu \mathrm{g}$ $\mathrm{mL}^{1}$ ). Soluble CD 14 concentration declined over the time to values of $41.12 \pm 11.91 \mu \mathrm{g} \mathrm{mL} \mathrm{m}^{-1}(>7$ day postpartum). They also reported that, the soluble form of the receptor critically involved in innate recognition of bacteria, $\mathrm{SCDI} 4$, is present and at high concentration in human milk. Furthermore, they showed that sCD14 can mediate IEC cell activation induced by endo-toxin and whole bacteria, resulting in the production of potent immune response and pro-inflammatory mediators. Importantly, they found that differentiated mammary epithelial cells are able to produce sCD14 whose molecular pattern is identical to that of sCD14 present in human milk during most of the lactating period. They considered two possible roles of sCD14: in protection of the mammary gland against bacterial infection during lactation and in protection of neonatal gut (Labeta et al., 2000).

Vidal et al. (2001) reported that human breast milk had higher levels of sCD14 $(14.84 \pm 6.39 \mu \mathrm{g}$ $\left.\mathrm{mL}^{-1}\right)$. The highest levels of sCD14 $(20.10 \pm 8.74 \mu \mathrm{g}$ $\mathrm{mL}^{-1}$ ) was detected within the first week postpartum, decreased to $\left(13.09 \pm 4.31 \mu \mathrm{g} \mathrm{mL} \mathrm{m}^{-1}\right)$ in samples collected later. This molecule is involved in innate immune responses and may control mechanisms of homeostasis in the neonatal intestine.

In the present study, we confirmed that human milk is a very rich source of Sialic acid, which plays an important role in increasing the immunity of breast fed infants.

We revealed that levels of Sialic acid were significantly higher in group-I $\left(3.29 \pm 1.34 \mathrm{mmol} \mathrm{L}^{-1}\right)$ and in group-II $\left(3.99 \pm 1.32 \mathrm{mmol} \mathrm{L}^{-1}\right)$ compared with group-III $\left(1.30 \pm 0.16 \mathrm{mmol} \mathrm{L}^{-1}\right)(\mathrm{p}>0.0001)$.
Miller et al. (1994), found that human milk showed significant declines in Sialic acid concentrations with duration of lactation; Sialic acid concentrations in colostrums were 5 times higher than were concentrations in mature milk after 3 months. However, concentrations of Sialic acid in mature milk (1 month of lactation) varied 2-fold among full-term and 3-fold among the preterm group. Sialic acid, therefore, is one of the most variable fractions of human milk. They also found that milk from the preterm group was an even greater source of Sialic acid than was milk from the full-term group at all stages.

Sialic acid was also found in small but significant amounts in the free form. Average concentrations of 0.14 and $0.19 \mathrm{mmol} \mathrm{L}^{-1}$ were found in the colostrums of mothers from the full-term and preterm groups, respectively, but by 3 months of lactation, the concentrations had decreased to 0.026 and $0.03 \mathrm{mmol}$ $\mathrm{L}^{-1}$. By contrast, infant formulas contained $<0.01 \mathrm{mmol}$ free sialic acid $\mathrm{L}^{-1}$. The significance of the free form is not known but may reflect the metabolic status of sialic acid or its availability in the mammary gland because concentrations dropped with decreases in the oligosaccharide-bound and protein-bound forms of sialic acid in human milk (Carlson, 1985).

Breast fed infants have a lower risk of diarrhea than infants fed milk substitutes. Heretofore, this had been most commonly attributed to the antibody content of human milk. Fucosyl oligosaccharides in human milk are significantly associated with lower risk of diarrhea in breastfed infants, suggesting a major role for these oligosaccharides in immunity (Newburg et al., 1990).

In the present study we observed that human breast milk had high levels of L-Fucose $(8.84 \pm 0.34 \mathrm{mmol}$ $\left.\mathrm{L}^{-1}\right),\left(8.92 \pm 0.37 \mathrm{mmol} \mathrm{L}^{-1}\right),\left(5.80 \pm 1.96 \mathrm{mmol} \mathrm{L}^{-1}\right)$ in group-I, group-II and group-III respectively.

The statistical analysis revealed that, there was no significant difference between group-I and group-II. However, there was a significant difference when group-I and group-II were compared separately to group-III.

The highest concentrations of HMOs can be found in colostrums $\left(20 \mathrm{~g} \mathrm{~L}^{-1}\right)$, but even mature milk contains oligosaccharides in concentrations up to $13 \mathrm{~g} \mathrm{~L}^{-1}$ (Coppa et al., 1993).

Earlier reports indicated that colostrum (1-3 days postpartum) contains double the concentration of oligosaccharides found in mature milk and that the concentration of total oligosaccharides decreases in the first 120 days of lactation (Coppa et al., 1993)

Enterotoxigenic E.coli produces a Secretory Toxins (ST) that causes diarrhea. ST-induced diarrhea, in mice can be inhibited by human milk (Deary et al., 1983). 
This inhibitory activity is due to a «1,2-linked fucosylated oligosaccharide (Newburg et al., 1990). These fucosyl-oligosaccharides inhibit binding of stable toxin of E. coli to its host cell receptor in vitro. 1, 2Linked fucosyl-oligosaccharides present in human milk playing a major role in providing significant protection to breastfed infants against different strains of E. coli.

However, diarrhea associated with secretory toxins ST-E.coli accounts for less than $2 \%$ of total diarrhea cases in our population. Other more common enteric pathogens include campylobacter and noroviruses. Campylobacter binds to 2-linked fucosyl moieties of intestinal glycoconjugates and its binding and infection are inhibited in vitro and in vivo by human milk fucosyl-oligosaccharides that have a 2-linked moiety, specifically the H-2 epitope. Norovirus binding is also inhibited by fucosylated $\alpha-1,2$-linked glycans (Huang et al., 2003).

\section{CONCLUSION}

It appears that sCD14, L-Fucose and Sialic acid found in breast milk may play a biovital role in the immunity of the neonates by providing protection to the suckling infants at a time when its immune system is still immature. We believe that the breast feeding is essential to protect infants and to enhance their immunity.

Future studies should be carried out in order to examine and understand the mechanism of action of these compounds related to the immune system of neonates.

\section{REFERENCES}

Bao, Y., L. Zhu and D.S. Newburg, 2007. Simultaneous quantification of sialyloligosaccharides from human milk by capillary electrophoresis. Anal. Biochem., 370: 206-214. DOI: 10.1016/j.ab.2007.07.004

Bazil, V. and J.L. Strominger., 1991. Shedding as a mechanism of down-modulation of CD14 on stimulated human monocytes. J. Immunol., 147: 1567-1574.

Brandtzaeg, P., 2003. Mucosal immunity: Integration between mother and the breast-fed infant. Vaccine, 21: 3382-3388. PMID: 12850345

Calisher, C.H., 2008. Immunologists: What are these people talking about? Croat Med. J., 49: 272-278. DOI: $10.3325 / \mathrm{cmj} .2008 .2 .272$

Carlson, S.E., 1985. N-acetylneuraminic acid concentrations in human milk oligosaccharides and glycoproteins during lactation. Am. J. Clin. Nutr., 41: 720-726. PMID: 4039105
Coppa, G.V., O. Gabrielli, P. Pierani, C. Catassi and A. Carlucci et al., 1993. Changes in carbohydrate composition in human milk over 4 months of lactation. Pediatric, 91: 637-641. PMID: 8441573

Field, C.J. 2005. The immunological components of human milk and their effect on immune development in infants. J. Nutr., 35: 1-4. PMID: 15623823

Hanson, L.A., M. Kortotkova and E. Telemo, 2003a. Breast-feeding, infant formulas, and the immune system. Ann. Allergy Asthma. Immunol., 90: 59-63 PMID: 12839115

Hanson, L.A., M. Kortotkova, S. Lundin, L. Haversen and S.A. Silfverdal et al., 2003b. The transfer of immunity from mother to child. Ann. N Y. Acad. Sci., 978: 199-206. PMID: 12727640

Huang, P., T. Faraks, S. Marionneau, W. Zhong and N. Ruvoen-Cloutet et al., 2003. Noroviruses bind to human ABO, lewis, and secretor histo-blood group antigens: Identification of 4 distinct strain-specific patterns. J. Infect. Dis., 188: 19-31. PMID: 12825167

Kelly, D. and A.G. Couttes, 2000. Early nutrition and the development of immune function in the neonate. Proc. Nutr. Soc., 59: 177-185. PMID: 10946785

Labeta, M.O., K. Vidal, J.E. Nores, M. Aarias and N. Vita et al., 2000. Innate recognition of bacteria in human milk is mediated by a milk-derived highly expressed pattern recognition receptor, soluble CD14. J. Exp. Med., 191: 1807-1812. PMID: 10811873

LoCascio, R.G., M.R. Ninonuevo, S.L. Freeman, D.A. Sela and R. Grimm et al., 2007. Glycoprofiling of bifidobacterial consumption of human milk oligosaccharides demonstrates strain specific, preferential consumption of small chain glycans secreted in early human lactation. J. Agric. Food Chem., 55: 8914-8919. PMID: 17915960

Lopes, J.F. and E.M. Gasper, 2008. Simultaneous chromatographic separation of enantiomers, anomers and structural isomers of some biologically relevant monosaccharides. J. Chromatogr. A., 1188: 34-42. PMID: 18177879

Mackie, R.I., A. Sghir and H.R. Gaskins, 1999. Developmental microbial ecology of the neonatal gastrointestinal tract. Am. J. Clin. Nutr., 69: 1035S-1045S. PMID: 10232646

Mahfouz, M.H., H.M. Ghanem and M.A. Mohamed, 2010. Modulation of insulin receptor substrate-1 and some inflammatory variables in hyperinsulinemic rats treated with cinnamon extract. Am. J. Biochem. Biotechnol., 6: 11-18. DOI: 10.3844/ajbbsp.2010.11.18 
Miller, J.B., S. Bull, J. Miller and P. McVeagh, 1994. The oligosaccharide composition of human milk: Temporal and individual variations in monosaccharide components. J. Pediatr Gastroen. Nutr., 19: 371-376. PMID: 7876988

Newburg, D.S., L.K. Pickering, R.H. McCluer and T.G. Cleary, 1990. Fucosylated Oligosaccharides of human milk protect suckling mice from heatstabile enterotoxin of escherichia coli. J. Infect. Dis., 162: 1075-1080. PMID: 2230234

Ninonuevo, M.R., R.E. Ward, R.G. LoCascio, J.B. German and S.L. Freeman et al., 2007. Methods for the quantitation of human milk oligosaccharides in bacterial fermentation by mass spectrometry. Anal. Biochem., 361: 15-23. PMID: 17181994

Plucinsky, M.C., W.M. Riley, J.J. Prolok and J.A. Alhadeff, 1996. Total and lipid-associated serum sialic acid levels in cancer patients with different primary sites and differing degrees of metastatic involvement. Cancer, 15: 2680-2685. PMID: 3779617

Ulevitch, R.J. and P.S. Tobias, 1995. Receptordependent mechanisms of cell stimulation by bacterial endotoxin. Ann. Rev. Immunol., 13: 437457. PMID: 7542010
Vidal, K., M.O. Labeta, E.J. Schiffrin and A. DonnetHughes, 2001. Soluble CD14 in human breast milk and its role in innate immune responses. Acta. Odontol. Scand., 59: 330-334. PMID: 11680654

Wang, B. and J. Brand-Miller, 2003. The role and potential of sialic acid in human nutrition. Eur. J. Clin. Nutr., 57: 1351-1369. DOI: 10.1038/sj.ejcn.1601704

Ward, R.E., M. Ninonuevo, D.A. Mills, C.B. Lebrilla and J.B. German, 2006. In vitro fermentation of breast milk oligosaccharides by bifidobacterium infantis and lactobacillus gasseri. Appl. Environ. Microbiol., 72: 4497-4499. PMID: 16751577

Wright, S.D., R.A. Ramos, P.S. Tobiass, R.J. Ulvitch and J.C. Mathison, 1990. CD14, a receptor for complexes of lipopolysaccharide (LPS) and LPS binding protein. Science, 249: 1431-1433. PMID: 1698311

Yu, S., N. Nakashima, B.H. Xu, T. Matsuda and A. Izumihara et al., 1998. Pathological significance of elevated soluble CD14 production in rheumatoid arthritis: In the presence of soluble CD14, lipopolysaccharides at low concentrations activate RA synovial fibroblasts. Rheumatol. Int., 17: 237243. PMID: 9592864 